\title{
INTEGRAÇÃO FAMÍLIA-ESCOLA: A EXPERIÊNCIA DE UM ESTÁGIO EM EDUCAÇÃO E COMUNIDADE
}

\author{
Fernando César Paulino-Pereira* \\ Maria Fernanda da Cruz** \\ Shirlei Neves Debussi***
}

\begin{abstract}
Resumo:O papel do psicólogo escolar é atuar de acordo com o papel de educador, ajudando a aumentar a qualidade e a eficiência do processo educacional através da aplicação dos conhecimentos psicológicos. Os objetivos do artigo, de revisão de literatura e análise documental, são: fazer levantamento da importância de um estágio de integração família-escola; entender como a família pode ser integrada à escola a partir de um projeto de estágio; verificar se essa relação família-escola se torna mais próxima a partir das intervenções propostas pelas estagiárias do projeto. O estudo tem relevância científica e social, pois serve como parâmetro para outros pesquisadores que querem estudar a integração família-escola, bem como a importância das atividades feitas com os pais, buscando uma melhor qualidade em seus relacionamentos com seus filhos, bem como com a instituição de ensino. Esta pesquisa teve como método de investigação o levantamento bibliográfico a respeito do problema referido; levantamento documental dos diagnósticos e projetos de intervenção feitos pelas estagiárias do programa de estágio em 2003 e 2004; por fim, descrição dos relatórios finais de estágio.
\end{abstract}

Palavras-chave:Integração família-escola, psicologia; escolar e educacional; pais e filhos. 


\section{Introdução}

O presente artigo suscita uma questão levantada há duas décadas , mas que ainda é tema relevante (mesmo que camuflado no discurso de educadores) na vida escolar de muitos meninos e meninas.

Ainda hoje transitamos por duas histórias relacionadas à classe social e, conseqüentemente, às formas de relação esperadas ou já préestabelecidas da família e a escola. A primeira e mais confortável referese a uma concepção de educação que coloca a escola como extensão da família das classes mais favorecidas; e a outra sacramenta a escola como um meio de salvação, como o único recurso que pode favorecer algum tipo de ascensão profissional ou melhoria de vida. A participação das famílias, nos dois casos, difere-se pelas expectativas e prognósticos estabelecidos pelos próprios grupos.

Nesse contexto, ao investigar o cotidiano onde vivem tais crianças, constatamos o desconforto dos educadores, que buscam na família o suporte para o desenvolvimento do aluno em sala de aula. O fato é que este cenário provoca um fenômeno interessante no âmbito escolar. Segundo Guimarães (1999), a relação família - escola está de certa maneira difusa e, como consequiência, os educadores ficam sem referência, uma vez que a escola é chamada a assumir determinados papéis na educação do aluno, que são reconhecidos como de competência familiar, para os quais não se encontra preparada. Nesse contexto, temos a escola, responsável pelo desenvolvimento do aluno durante um período importantíssimo de sua vida, cobrando a presença dos pais e, ao mesmo tempo, erigindo um muro de proteção em torno de sua prática e função pedagógica.

O objetivo deste artigo, que resulta do acompanhamento de um programa de estágio em psicologia da educação direcionado a pais de alunos, realizado nos anos de 2003 e 2004, é: a partir da revisão de literatura e análise documental; objetivar a importância do estágio de Psicologia Social e Educacional direcionado à integração família -escola. Esta pesquisa teve como método de investigação o levantamento bibliográfico sobre a questão apresentada e o levantamento documental dos diagnósticos e projetos de intervenção feitos por estagiárias do curso de Psicologia da UNIARARAS, nos anos de 2003 e 2004 e, por fim, há a descrição dos relatórios finais de estágio. 


\section{Escola: cotidiano e preconceito}

Segundo Maluf (1994), a tarefa de educar não tem idade, mas é em meados de 1970 que acontece um período de críticas aos resultados educacionais obtidos até então. Segundo o autor, algumas pesquisas, no intuito de levantar dados a respeito de fontes bibliográficas referentes à formação e atuação do psicólogo escolar de 1980-1992, concluíram que um grande número de publicações se atém aos aspectos clínicos e psicométricos da atividade do psicólogo, sobretudo junto às escolas de $1^{\circ}$ grau e em consultórios; houve também uma insatisfação manifesta a respeito do tipo de formação que os cursos de psicologia oferecem ao futuro profissional e do tipo de atuação ainda predominante.

O autor acima citado traz a informação de que a psicologia educacional, mesmo quando passou a ter certo caráter preventivo, não se afastou do modelo clínico e continuou tratando o indivíduo como centro de um problema, o rendimento escolar, cuja origem é multideterminada e que é socialmente influenciado, mesmo nos casos em que sua base é de natureza orgânica (MALUF, 1994).

Para Reger (1981), o psicólogo clínico, mesmo quando se encontra num estabelecimento acadêmico, baseia-se principalmente em um modelo médico, mais do que em um modelo acadêmico, seu interesse gira em torno da saúde mental e do diagnóstico e cura de problemas do comportamento humano. O que nos parece estranho é que a escola como instituição é tomada como adequada, cumprindo os objetivos ideais a que se propõe e, assim, permanecem inquestionáveis o anacronismo dos currículos, dos programas, das técnicas de ensino-aprendizagem, como se os problemas estivessem apenas centrados no aluno. Na medida em que os problemas são equacionados em termos de saúde $\mathrm{x}$ doença, fica o papel do psicólogo investido de um caráter onipotente, uma vez que seria o portador de soluções mágicas para as dificuldades enfrentadas.

Uma alternativa adequada e que não exclui a defendida por Reger seria a do psicólogo escolar como agente de mudanças dentro da instituiçãoescola, onde funcionaria como um elemento catalisador de reflexões, um conscientizador dos papéis representados pelos vários grupos que compõem a instituição. Vimos através de Moysés e Collares (1996) que uma das características fundamentais da vida cotidiana é a existência de juízos 
provisórios de valor. Quando um juízo provisório é refutado no confronto com a realidade concreta, seja através da Ciência, seja por não encontrar confirmação nas experiências de vida do indivíduo e mesmo assim se mantém inabalável contra todos os argumentos da razão, não é mais juízo provisório e sim preconceito.

Para Heller (1989, p.43): "o preconceito é a categoria do pensamento e do comportamento cotidiano". A escola vê preconceituosamente o cotidiano das crianças das classes menos favorecidas, a sua história de vida e de suas famílias. É comum ouvirmos que as crianças não aprendem porque são pobres, negras, nordestinas e que seus pais não têm condições de ensiná-las, pois na maioria das vezes são alcoólatras, analfabetos ou trabalham muito, não tendo tempo de dar a devida atenção a seus filhos. Assim, a escola se apresenta como vítima de uma clientela inadequada, como se os problemas estivessem nas crianças e não na forma como elas são preconceituosamente vistas. "Crer em preconceitos é cômodo porque nos protege de conflitos, porque confirma nossas ações anteriores" (HELLER, 1989, p.48).

Preconceitos esses que atribuem à criança características inerentes a sua não-alfabetização, transformando questões sociais em biológicas. Como exemplo, na década de 1960, pesquisas científicas "comprovaram" a superioridade intelectual do homem branco sobre o negro (MOYSÉS e COLLARES, 1996). Ao biologizar questões sociais, há uma perda de responsabilidade de todo sistema social e a "vítima acaba sendo culpada".

Conforme Moysés e Collares (1996), através de estudos realizados nas décadas de 1950 a 1970, em relação à desnutrição e ao desenvolvimento do Sistema Nervoso Central, foi possível perceber que a desnutrição só pode afetar o Sistema Nervoso Central quando for de grave intensidade, ocorrer no início da vida (até os dois anos), durante o desenvolvimento mais inicial do Sistema Nervoso Central e quando se estender por um longo espaço de tempo. Entretanto, um possível déficit cognitivo ou de outras características mentais ou emocionais não pode ser comprovado cientificamente, pois é impossível determinar qual o potencial de cada indivíduo. Segundo estes estudos citados por Moysés e Collares (1996), foi possível afirmar que a maioria das crianças que desenvolvem desnutrição grave morre antes dos cinco anos de idade, sendo assim questiona-se: como surge esse discurso de que a desnutrição interfere na alfabetização? 
Segundo Patto (1990), estamos num país de desnutridos, mas estamos também num país onde as crianças morrem antes de completar um ano de idade. Exatamente por isso, colocar a desnutrição como causa do fracasso escolar não tem lógica, já que a criança desnutrida dificilmente chega à idade de freqüentar os primeiros anos escolares. Outra forma de preconceito está posta em relação às Disfunções Neurológicas, englobando problemas como a hiperatividade, os distúrbios de aprendizagem em geral e a dislexia. Todas possuem um padrão de comportamento que incomoda a instituição escolar, pois difere das normas socialmente estabelecidas. A dislexia é uma das formas mais frequentemente usadas para caracterizar e rotular um distúrbio de aprendizagem. Segundo Hinshelwood (1896, apud MOYSÉS E COLLARES, 1996), oftalmologista inglês, se uma lesão neurológica compromete o domínio da linguagem escrita, é possível que quem não consiga ler possa ter uma lesão neurológica. Segundo Moysés e Collares (1996), essa hipótese ainda não foi comprovada, pois não teve nenhum respaldo científico, apenas juízos provisórios que acabam se transformando em preconceito.

A quantidade de pesquisas que demonstram a inconsistência das afirmações sobre "distúrbios de aprendizagem" é muito grande, porém com divulgação restringida, principalmente no Brasil. Apenas como exemplo, podemos citar alguns autores de renome: VERNON, CONRAD, MILLER, VELLUTINO, COLES, BLACK, SCHECHTER (MOYSÉS ECOLLARES, 1996, p. 21).

É importante ressaltar que todo esse sistema de preconceitos se encontra subjacente a um promissor mercado de trabalho para várias profissões, com a proliferação de clínicas para tratamento de "distúrbios" de aprendizagem ou de comportamento. Para uma sociedade que difunde os ideais de igualdade e de oportunidades para todos e da ascensão social via escola, esse preconceito é suficiente para que o excluído socialmente se considere responsável pelo seu "fracasso". Heller (1989) nos mostra que grande parte dos preconceitos são produtos das classes dominantes. A universalização da ideologia burguesa pode ser concretamente observada quando uma professora exclui, marginaliza uma criança, cujo único defeito é pertencer a uma classe social já marginalizada. 
Segundo Patto (1990), o cotidiano escolar é o espaço onde se concretiza a produção do fracasso escolar. Se rompermos esses preconceitos; será possível construir uma escola politicamente comprometida com a classe trabalhadora. É fundamental que se invista cada vez mais na formação do professor, permitindo-lhe apropriar-se de novos conhecimentos científicos, novas teorias educacionais. Porém, se esses investimentos não tiverem como objetivo interferir no cotidiano escolar e romper preconceitos, a causa das crianças continuarem não se alfabetizando; continuará sendo doenças inexistentes, famílias omissas, etc. Enfim, a escola continuará sendo "vítima de uma clientela inadequada".

Perguntamos: até que ponto tais afirmações referentes às crianças de camadas populares não passam de afirmações de caráter ideológico, que justificam uma ordem social vigente com uma roupagem aparentemente científica? É comum o discurso das professoras pedindo para que as mães levem seus filhos ao médico, com a queixa de que os mesmos estão "indo mal na escola". Como conseqüências do tratamento medicamentoso, não viriam efeitos colaterais que acabariam afetando o rendimento da criança em aula, confirmando ao professor que aquela criança realmente não tem condições de aprender?

Segundo Patto (1990), é necessária a passagem do discurso da deficiência para o discurso da diferença, em que se afirma que as crianças das camadas populares não têm deficiência de linguagem, mas falam uma linguagem diferente da criança de classe média, resolvem problemas de forma diferente, mesmo porque seus problemas são diferentes; e têm toda uma experiência de vida diferente das crianças de classe média. As dificuldades de aprendizagem, nesse contexto, dever-se-iam ao fato de que a escola não estaria levando em conta essas diferenças, e os professores estariam esperando a presença, nos bancos escolares, de uma criança idealizada. O que vemos então é a necessidade de adequar a escola à realidade dessa criança e a sua maneira de ser.

Sendo assim, não podemos nos esquecer da importância da família na escolarização - sob o risco do discurso dos autores reforçar o que está sendo criticado - , a família pode acompanhar o desenvolvimento escolar da criança, mas não pode ser responsabilizada pela qualidade 
desse "rendimento" dessa criança. Para Bencini (2003) é muito importante que os pais acompanhem a lição de casa, que não faltem a nenhuma reunião, enfim, que se mostrem atentos ao desempenho escolar. O Sistema nacional de Avaliação da Educação Básica, de 1999, apontou que nas escolas que contam com a parceria dos pais num envolvimento participativo das famílias - os alunos aprendem melhor.

Diversos educadores brasileiros também defendem que a família realize um acompanhamento da escolarização, verificando se os objetivos escolares estão sendo devidamente alcançados (BENCINI, 2003). Segundo Bencini (2003), a atuação dos pais ainda é bem rara nesse processo e a maior parte dos educadores atribui àqueles a origem dos problemas de disciplina. Apontam como fatores o novo modelo familiar, no qual os adultos permanecem pouco tempo em casa; ou ainda aquele que apresenta uma organização diferente da tradicional.

\section{A importância da família na escola}

A educação dada pela família dá suporte para que o ser humano possa agir e agindo se materialize enquanto sujeito da sua própria história. Do ponto de vista biológico, o homem é o mais frágil dos animais, pois necessita de relações afetivas para sua saúde mental, portanto a família tem o papel de promover a superação do egocentrismo infantil, tornando o adulto disponível para o convívio social.

O desafio da família contemporânea é possibilitar momentos para que haja mais diálogo, pois o ritmo desgastante da vida moderna está impedindo o cultivo dos afetos humanos, prejudicando a qualidade de vida. A família moderna retirou da vida comum não apenas as crianças (tornando distintas atividades "próprias" para as crianças e outras "próprias" para os adultos), mas uma grande parte do tempo e da preocupação dos adultos. Percebe-se então uma necessidade de intimidade e, também de identidade em que os membros da família se unem pelo sentimento, o costume e o gênero de vida (ARIÉS, 1981).

Em Simionato-Tozo e Alves (1996) encontramos um estudo com o objetivo de analisar dados que descrevem o processo de escolarização de crianças nas décadas de 1960/1970 e 1980/1990, visando traçar 
comparações e identificar possíveis variáveis associadas às mudanças observadas. Os autores ressaltam que a relação entre a educação escolar e a sociedade, em diferentes momentos históricos, foi determinando o papel que a educação deveria cumprir, de acordo com os interesses sócio, econômico, políticos dominantes em diferentes momentos.

Segundo Penin (apud SIMIONATO- TOSO E ALVES, 1996), nas últimas décadas o sistema público de ensino foi marcado por três fenômenos que determinaram fortemente sua atual configuração. $\mathrm{O}$ primeiro foi o processo de burocratização, devido à penetração da tendência tecnicista da educação em nosso país. O segundo, o processo de democratização da escola, que resultou em uma súbita ampliação da rede de ensino e no aumento da heterogeneidade da clientela escolar devido ao acesso à escola de crianças provenientes das camadas populares. E o terceiro relaciona-se a desvalorização da profissão docente, que levou profissionais a assumirem jornadas maiores de trabalho, interferindo na qualidade da atuação profissional.

Volnovich e Huguet (1993) acrescentam que a dissolução do poder do Estado tem criado a sensação de que qualquer um pode governar, sem alterar o fato de que o próprio Estado já não tem responsabilidade sobre os cidadãos, muito menos em se tratando de crianças. Neste campo de desagregação do modelo paternalista assistencialista e da responsabilidade do Estado, a escola regular "produz" a escolarização de muito mais crianças atípicas do que supostamente "normais", sendo que as primeiras compõem a massa que será atendida pela educação especial e pelos milhares de consultórios particulares, segundo Volnovich e Huguet (1993). Os pais também consideram conveniente esta política porque, de alguma forma, o filho não fica na rua, pode aprender, fazer terapia e até chegar a uma profissionalização; acabam sendo inocentados: o Estado, as instituições, os profissionais e os pais.

Entendemos que esta política tem dissolvido as individualidades num universo de consumidores, onde as crianças aparecem na categoria de usuários. Segundo pesquisa feita por Szymanski (2004), o processo de socialização se dá no convívio familiar e, em especial, por meio das práticas educativas desenvolvidas com a finalidade de transmitir hábitos, valores, crenças e conhecimentos, que se acredita serem úteis para a 
inserção dos filhos na sociedade. "É na família que a criança encontra os primeiros" outros "e, com eles aprende o modo humano de existir" (SZYMANSKI, 2004, p.7). Assim, seu mundo adquire significado e ela começa a constituir-se como sujeito. Isto se dá na e pela troca intersubjetiva, construída na afetividade que, constitui o primeiro referencial para a sua constituição identitária.

Ao se pensar em família como lócus de desenvolvimento, deve-se lembrar que elas [famílias] divergem quanto à concepção de infância e, em conseqüência, irão possibilitar diferentes oportunidades à criança (SZYMANSKI, 2004, pág 9).

Porém, a escola enquanto instituição social tem como função possibilitar o acesso das crianças à cultura letrada, reafirmando os valores, habilidades e conhecimentos que a sociedade considera importantes (KLEIMANapud SIMIONATO-TOSO, 1996). O processo de escolarização sofre transformações para responder as mudanças impostas pela sociedade, principalmente pela família. O rápido aumento do número de mães que ingressam no mercado de trabalho acarreta a transformação no cuidado diário de crianças pequenas, havendo a expansão de instituições públicas e privadas com este objetivo (SOMMER E LANGSTED Sommer e Langsted apud SIMIONATO-TOSO, 1996).

Nesse sentido, é de excepcional importância a proposta pedagógica da escola, que deve ser vista como a explicitação oficial de cada interveniente no processo. Por isso, é importante que seja elaborada junto às famílias, professores e técnicos, sendo passível de crítica permanente e prevendo mecanismos objetivos de ausculta aos interesses da comunidade educativa, facilitando um processo permanente de avaliação institucional e funcional.

Segundo Silva e Vargas (2003), a qualidade participativa na relação família-escola precisa ser repensada e melhor organizada pela escola, para que o processo participativo seja ampliado. Quanto à comunicação existente entre família e escola, ficou muito clara a importância da interlocução atenta para a identificação de desejos e intenções nãoditas, assim como para a troca sobre as experiências vividas pela 
criança no contexto familiar e escolar.

Não é possível pensar na Escola sem pensar na Família quando a questão em discussão é o desenvolvimento da criança em qualquer segmento escolar. Estudo realizado por Silva e Vargas (2003) "confirmou que uma correlação positiva entre família e escola, no que diz respeito a transparências das ações construídas e participativas, favorece a visibilidade das práticas educativas e o valor social da educação institucionalizada" (p. 34).

A escola deve então, segundo Bencini (2003), utilizar todas as oportunidades de contato com os pais para - num envolvimento participativo das famílias - socializar informações relevantes sobre seus objetivos, recursos, problemas e também sobre questões pedagógicas. Só assim eles vão se sentir comprometidos com a melhoria da qualidade escolar.

\section{3. integração família-escola: novas propostas para velhos dilemas}

Neste tópico concentramos as ações das estagiárias de 2003 e 2004 no Estágio Integração Família-Escola. Este estágio aborda a área da Psicologia Educacional num programa integrado entre Educação e Comunidade, nos anos de 2003 e 2004. Este estágio teve como objetivo geral: "Desenvolver intervenções que visem ações coletivas entre família e escola, na busca de equacionamento para as problemáticas educacionais enfrentadas no cotidiano institucional".

Foi realizada uma parceria entre a Uniararas e a Prefeitura Municipal de Araras, sendo o local do estágio uma escola (CAIC Centro de Atenção Integral à Criança, com cerca de 500 alunos, 50 funcionários e 90 professoras - comportando dois períodos, diurno e vespertino, de berçário a $4^{\mathrm{a}}$ série do ensino fundamental), localizada no Parque Tiradentes (periferia, há aproximadamente $15 \mathrm{~km}$ do centro da cidade, bairro onde residem pessoas, que na estratificação social, econômica capitalista encontram-se desprivilegiada - empobrecidas), na cidade de Araras- SP.

O projeto de estágio enfocou a integração família-escola, e o primeiro passo foi realizar um diagnóstico institucional (onde foi detectada a falta 
de integração família-escola: foram ouvidos $50 \%$ os pais [2003] e $80 \%$ dos pais [2004] e 100\% dos funcionários [2003 e 2004], através de reuniões, entrevistas e questionários. A partir disto, elaborou-se um projeto de intervenção para propiciar esta integração, através de reuniões de pais e mestres, plantões para atendimento de pais, encontros semanais com grupos de pais.

\subsection{O que foi diagnosticado, proposto e realizado em 2003 O Diagnóstico de 2003}

O primeiro contato com a instituição ocorreu no dia $1^{\circ}$ de Abril de 2003, numa visita feita pelas estagiárias juntamente com o supervisor do estágio. Nesta visita a direção se colocou à disposição para auxiliar no projeto. Após a apresentação das estagiárias à instituição, relatouse os seguintes problemas que atingem a instituição, como falta de participação e interesse dos pais na vida escolar dos filhos.

A partir daí - para um possível diagnóstico, foram feitas entrevistas com os funcionários da instituição: professores, merendeiras, serventes, porteiros, secretárias, inspetores de alunos, direção, com o objetivo de verificar como era realizado o contato com os pais e o acesso à escola (todos os funcionários foram ouvidos neste momento, ou seja, cem por cento da escola).

Nas falas das professoras e funcionários não só apareciam reclamação e informação sobre a relação família-escola como foram apresentadas sugestões, visando orientar os pais na educação de seus filhos:

"Vocês precisam achar um jeito de chamar os pais de outras formas, com algo que desperte a atenção deles" (Diagnóstico 2003, p. 8). “Uma coisa que poderia trazer os pais à escola é um curso de artesanato, por exemplo, ou palestras que falem de família, pois as famílias são todas desestruturadas" (Diagnóstico 2003, p. 8).

O contato com os pais se deu em dois momentos: primeiramente foi elaborado um questionário que tinha como objetivo levantar dados sobre a história escolar das famílias e denominar em quais momentos 
os pais estabeleciam contato com a instituição, e se tinham sugestões a apresentar. Esse questionário foi enviado através de alguns alunos escolhidos aleatoriamente, foram entregues a 80 crianças, das quais obtiveram-se um retorno de $65 \%$. O outro contato foi realizado através da reunião bimestral, onde os pais eram reunidos no anfiteatro com as estagiárias que se apresentaram e falaram sobre o trabalho que realizariam na escola, convidando os pais para participarem dos grupos que ali aconteceriam (compareceram aproximadamente 250 pais).

A partir dos dados coletados foi verificado que o projeto (Integração Família-Escola) é de suma importância para uma melhor relação da família com a escola, objetivando uma melhor qualidade da relação PaisEscola e também no que diz respeito à aprendizagem para as crianças e demais pessoas envolvidas. Após dois meses de convívio na escola, as estagiárias levantaram os seguintes problemas e necessidades: como melhorar a relação entre os pais, professores e demais funcionários para que houvesse uma maior integração dos pais na escola, assim como oferecer ajuda para pais com pouca instrução, objetivando ajudá-los nas tarefas domésticas, oferecer maiores informações para auxiliá-los no planejamento familiar, dar parâmetros para que tenham uma maior autoridade sobre seus filhos sem deixá-los ausentes de afeto e, assim, proporcionar maior respeito com colegas e professores, dar mais informações aos professores a respeito da progressão continuada, e orientar melhor os pais da importância de comparecer às reuniões.

Observou-se, neste período, que o cotidiano escolar está repleto de preconceitos - é mais fácil dizer que a criança não aprende porque é pobre, desnutrida, suja, enfim... que não tem condição nenhuma de desenvolvimento pois, não há afeto e seus pais são analfabetos. Segundo Patto (1990), o cotidiano escolar é o espaço onde se concretiza a produção do fracasso escolar. Por isso, é importante que os professores sejam melhores preparados, conseguindo romper com tais preconceitos para que isso não auxilie ainda mais na produção do fracasso escolar.

\section{A Proposta de Intervenção em 2003}

O projeto de estágio teve como proposta realizar uma maior integração entre a comunidade de pais e a escola, proporcionando um 
maior contato entre a família e a instituição, com o objetivo de discutir e debater dúvidas relacionadas ao universo escolar, favorecendo a participação dos pais na aprendizagem de seus filhos.

Isso foi realizado através de encontros e discussões sobre assuntos do cotidiano escolar e também familiar - era um espaço que pais e estagiárias tinham para tirar dúvidas e orientar os pais quanto ao desenvolvimento de seus filhos.

A proposta constava de formação de grupos de pais, participação nas reuniões de pais e mestres, plantões para atendimento dos pais que queriam conversar sobre a relação com seus filhos, em encontros semanais com grupos de pais, nos quais abordaram diversos temas que foram escolhidos em conjunto, como: conversas com crianças, novos métodos de elogiar e criticar, como evitar os métodos derrotistas, responsabilidade e independência, disciplina, tolerância e limites, um dia na vida da criança, o ciúme, algumas origens da ansiedade nas crianças, a educação sexual, pais que necessitam de auxílio profissional. Além dos temas sugeridos acima, outros foram propostos pelos pais, como: função do Conselho Escolar, função da APM (Associação de Pais e Mestres), temas relacionados à ECA (Estatuto da Criança e do Adolescente).

\section{Sendo os objetivos:}

- Buscar o equacionamento para as problemáticas educacionais enfrentadas no cotidiano institucional através de ações coletivas entre a família e a escola;

- Formar grupos de pais;

- Realizar, nos trabalhos grupais, reflexões e dinâmicas de grupos, a fim de tornar claro o papel designado a cada uma das partes (pais e escola), a fim de que se proponha uma melhoria nas relações, criando espaços de fala e uma maior participação e integração entre os pais, filhos e escola;

- Orientar os pais, pedagógica e terapeuticamente, na educação diária dos seus filhos, bem como na participação do processo ensinoaprendizagem dos mesmos. 


\section{O que foi Realizado em 2003}

Para a realização do projeto, foram formados grupos de pais para encontros semanais de aproximadamente uma hora e meia, durante nove semanas, abordando diversos temas escolhidos em conjunto com os pais no primeiro encontro, onde as estagiárias também apresentaram o projeto e seus objetivos.

O primeiro grupo formado iniciou-se em 04/08/2003 e contou com a participação de seis pais. Nesse primeiro encontro, além da escolha dos temas, estabeleceu-se o contrato (horário, participação) e foi falado sobre a questão do contrato de trabalho (sigilo, participação de todos, etc.). Isto passou segurança aos pais, que de início estavam um pouco tímidos e receosos em expor seus problemas e dificuldades nas relações com os filhos.

"Que bom que você falou isso... estava meio com medo, sabe como é, né... todos no bairro se conhecem...” (relatório final, Sofia, 2003, p. 14). "Agora fico mais segura, porque eu achava que viria aqui para ficar respondendo questões, e que amanhã todos do bairro estaria sabendo, porque o bairro é pequeno..." (relatório final, Paloma, 2003, pg. 13).

Os integrantes dos grupos eram pais e mães que tinham filhos estudando na instituição, bem como grupos com filhos. Também foram realizados grupos com pais e mães (da comunidade) que não tinham filhos que freqüentavam esta escola.

Os temas eram apresentados dinamicamente, com a participação de todos os pais, que contribuíam com relatos particulares sobre o assunto, enriquecendo as discussões. Foi preparado um resumo de cada tema que era entregue a eles no final do encontro, para terem acesso às informações quando precisassem.

Ao longo das reuniões, foi percebido um movimento de pessoas na constituição do grupo. Alguns chegaram tímidos, quietos, mas foram se familiarizando, trocando experiências, criando um clima descontraído e propício para a discussão dos temas.

A partir da frequiência no grupo, passaram a valorizar certas coisas 
que antes não fazia sentido, devido à falta de consciência de sua importância, como por exemplo,

"Elogiar a criança, negociar um desejo deles impossível no momento, como explicar sobre o sentimento de raiva e ciúmes pelos irmãos ou pais, como falar sobre sexo com os filhos, a função da APM e do Conselho, ete". (relatório final, Sofia, 2003, p. $15)$.

"Minha filha mais velha sente ciúme do Lucas, mas meu marido mima muito e apóia as criancices dele". (relatório final, Katiuscia, 2003,pg. 18).

As falas acima mostram como que as famílias participavam, trazendo questões do cotidiano para serem trabalhadas nos grupos; a confiança fez o grupo crescer; a partilha dos problemas fez com que o grupo se apoiasse mutuamente.

No último encontro do grupo, foi solicitado aos pais um feedback com relação ao aproveitamento dos conteúdos. Estes disseram ter provocado mudanças consideráveis na forma de agir e pensar a educação dos filhos: hoje não gritam tanto, não batem nas crianças, procuram conversar e explicar os fatos ao invés de impor ordens, assim abriram espaço para o diálogo e agora compreendem mais seus filhos e vice-versa.

"Eu sempre fui de só dar as ordens, gritar, deixar de castigo, bater, falar não, agora procuro falar mais baixo, dialogando, ouvindo as crianças". (relatório final, Paloma, 2003, pg. 16).

No grupo das crianças foram realizados treze encontros, uma vez por semana, com uma hora de duração. Ocorreu na sala de aula, próxima à secretaria da escola. Cada encontro foi iniciado por uma vivência, que tinha o objetivo de facilitar a integração do grupo com o tema proposto.

Em relação ao grupo da Katiuscia e Madalena, o encontro era realizado todas as quartas-feiras, às $14 \mathrm{~h}$ no Caic. Teve início com duas participantes, com o passar do tempo, no total, chegou a ter oito participantes em diferentes momentos, entretanto o maior número de participantes em um mesmo encontro foi de quatro pessoas. Eram 
três grupos no total, dois de pais e um com as crianças, filhos dos participantes dos grupos de pais, seja com esta dupla citada ou com a outra dupla Sofia e Paloma.

Foi possível perceber mudanças nas relações entre pais e filhos:

“o grupo me ajudou muito em casa com as crianças e até com meu marido, gostaria de participar do próximo grupo também, vou até trazer umas amigas que precisam" (relatório final, Paloma, 2003,pg. 14).

\subsection{O que foi diagnosticado, proposto e realizado em 2004 Diagnóstico de 2004}

A permanência na escola para realização do diagnóstico da instituição, que inclui o levantamento das necessidades da mesma, foi de aproximadamente 01 mês - iniciando-se no dia 16/03/04.

Para que as estagiárias conseguissem coletar dados precisos para realização do diagnóstico desta instituição e apresentar informações quanto às necessidades, foram divididas em duplas e apenas uma delas ficou sozinha.

As estagiárias tinham o intuito de saber quando ocorreria a reunião de pais, pois seria através desta atividade o estabelecimento de seus primeiros contatos com eles, a fim de realizarem a apresentação do projeto, da demonstração de uma das dinâmicas que estariam realizando no decorrer dos encontros e o convite de adesão ao projeto.

No período entre 16 de março a 08 de abril, data da última visita realizada na EMEIF, as estagiárias perceberam que algumas das mães entrevistadas tinham o mesmo intuito, pois informaram-nas sobre a rigidez das professoras. Com relação às visitas realizadas na EMEI, estas ocorreram no período de 17 de março a 20 de abril, devido à data que foi marcada para realização da reunião com os pais, objetivando também a apresentação do projeto, realização de uma dinâmica e convite de adesão dos pais ao projeto.

Desta forma, as reuniões ocorreram nos dias 13 e 15 de abril com os pais de alunos do Ensino Fundamental, foram aproximadamente 400 pais nos dois dias. Com os pais da EMEI e Creche subdividido em: berçário, onde ficam as crianças de 3 meses a 2 anos; maternal, 
correspondente às crianças de 2 a 3 anos; e EMEI, de 3 a 6 anos, a reunião foi realizada no dia 28 de abril.

Em relação à EMEI, foram apresentadas as seguintes necessidades:

"há uma restrita participação dos pais na escola, onde apenas comparecem quando seus filhos estão doentes; falta de preparo das professoras para lidarem com as crianças, pois foi observado que elas 'gritam e berram com as crianças', uma delas relatou que foi beliscada pela professora e que as 'crianças ficam abandonadas no parque, onde há alguns brinquedos inadequados para determinada faixa-etária"'(Diagnóstico, p. 13).

Além disso, foi verificada a necessidade do melhoramento das condições de higiene do berçário 1 , onde há apenas duas monitoras as quais, em alguns momentos, revezam para atenderem em média 14 crianças. A partir deste dado, podemos ressaltar também a importância do "aumento do quadro de funcionários" (Diagnóstico, p. 13) para que as crianças passem a receber os devidos cuidados.

Ainda com relação às crianças (do berçário), foi notado que são carentes de carinhos, pois "a maioria das crianças paravam de chorar quando eram pegas no colo" - isso demonstra a falta de profissionais suficientes para cuidar dos berçários, sobrecarregando um só funcionário para cuidar de vários bebês.

Foi notada a impossibilidade de participação dos pais nos instantes em que eram chamados para participarem da entrevista, decorrente de vários fatores, tais como: falta de tempo, sobrecarga de trabalho, jornada dupla de responsabilidades e o receio de ser chamado à escola do filho (Diagnóstico, p. 14).

Quanto às necessidades levantadas na EMEIF, a mais ressaltada pelas professoras, coordenadora e diretora, foi à baixa participação dos pais nas reuniões, fator também presente no diagnóstico da instituição realizado no ano anterior. A professora ressalta a existência de "não comprometimento" dos pais, pois alguns deles levam seus filhos, mesmo estando doentes, para a escola, sendo que ao professor é vedado o direito de medicar as crianças. Foi expresso também pelas professoras a necessidade da realização de trabalhos abordando os temas: orientação sexual e drogas. 
Além disso, as diretoras expressam preocupação quanto à excessiva falta dos alunos às aulas, tornando necessário a realização de uma reunião específica com os pais de alunos faltosos. Contudo, foi diagnosticada a discordância das professoras referente à utilização do método denominado progressão continuada. As professoras acreditam ser de suma importância a diminuição do número de alunos por sala de aula, para a melhoria do processo de ensino e aprendizagem.

Foi apontada a falta de explicação por parte da equipe psicopedagógica da secretaria municipal de educação, sobre os encaminhamentos das crianças para o ambulatório de saúde mental do município, sem que fosse dado aos professores e aos pais um retorno da situação dos motivos que os levaram a tomar tal decisão (Diagnóstico, p. 17).

$\mathrm{Na}$ entrevista realizada com as merendeiras que trabalham no período matutino, informaram que gostariam de ser mais respeitadas por parte dos alunos e dos próprios pais que relatam não valorizar seu trabalho.

Quanto ao contato estabelecido com as mães, as estagiárias foram informadas sobre a necessidade da existência de um guarda no portão da escola nos momentos em que as crianças chegam e saem da mesma, assim como, de acordo com o porteiro, melhoria na sinalização da rua em frente à escola. Além disso, foi apontado por alguns pais que os professores deveriam estar mais preparados para exercer a função de dar aula, pois, segundo eles, tem professoras que dizem para os alunos que o caderno está uma "caca" e o joga em cima da carteira (Diagnóstico, p. 18). Diante deste comentário e a partir da observação feita pelas estagiárias sobre a maneira com que os professores(as) agem em sala de aula percebeu-se que as professoras desconhecem que a classe é um lugar onde se tece uma complexa rede de relações e, desta forma, devem democratizá-la com o intuito de conquistar o aluno para o conhecimento.

Através das visitas, observou-se também que os pais precisam ser informados quanto à existência da APM, Associação de Pais e Mestres, com objetivos sociais, educativos e não religiosos, nem finalidades lucrativas. 


\section{A Proposta de Intervenção em 2004}

O trabalho proposto foi a realização de grupos com pais e grupos com as crianças, a fim de promover uma integração entre a família e a escola, possibilitando a interação dos pais com todos os profissionais da escola, podendo, assim, promover discussões sobre as divergências encontradas no contexto educacional e familiar, favorecendo a participação dos pais na aprendizagem de seus filhos.

Para isso, trabalharam com as demandas propostas e as sugeridas pelos próprios pais e educadores, através de dinâmicas e vivências, assuntos esses relacionados ao cotidiano escolar e familiar, fazendo uma integração entre ambas as partes, o que acabaria por facilitar o processo educacional das crianças.

O objetivo era de desenvolver intervenções que visem ações coletivas entre família e escola, na busca do equacionamento para problemas educacionais enfrentados no cotidiano institucional e familiar. Para isso, as estagiárias formaram grupos com os pais e seus respectivos filhos, salientando a especificidade psicológica no âmago dos processos grupais desencadeados a partir das atividades próprias à integração família-escola.

Através dos grupos realizaram dinâmicas e vivências, especificando o papel de cada um, o da escola e o dos pais, propondo, assim, uma melhor relação entre as partes, com mais participação por parte dos pais no cotidiano escolar dos filhos, realizando uma integração famíliaescola.

Nos grupos foram abordados assuntos relacionados ao cotidiano familiar e institucional, de acordo com a demanda. Os mesmos assuntos foram abordados no grupo com as crianças, com o intuito de serem agentes facilitadores do processo de integração da família na escola.

\section{O que foi Realizado em 2004}

O primeiro contato com as mães foi no portão da escola, as estagiárias se apresentaram e conversaram com elas a respeito da integração família-escola, perguntaram se elas tinham conhecimento do projeto que já existia no ano anterior e em que situações elas 
apareciam na escola. Logo depois, disseram não saber desse projeto e que o comparecimento delas na escola restringia-se apenas nas reuniões ou em queixas trazidas pelos filhos.

A partir dos primeiros contatos com a população escolar puderam ter um conhecimento da demanda ali existente. Uma professora afirma que:

\begin{abstract}
A classe é problemática, chamo os pais para a reunião e aparecem meia dúzia, os que precisam não vêm. Há diversos problemas, problemas de indisciplina, alunos que passam fome, problemas de fono, psicológicos, outros não conseguem nem ficar na sala de aula, também falta conscientização dos pais sobre a importância de acompanharem os processos escolares dos filhos, muitos não ligam, mandam os filhos doentes, acham que é obrigação dos professores educarem seus filhos (relatório final, Charlene e Rosane, pg. 16).
\end{abstract}

No relatório, as estagiárias questionam esta visão já instaurada e estigmatizada da relação Família-escola. A partir disso, foram criadas estratégias para a montagem dos grupos de pais: convites para as reuniões de pais, onde fariam uma apresentação do projeto. Conseguiram montar dois grupos de pais com 10 participantes em cada um, porém alguns não compareceram nem ao primeiro encontro e outros foram se ausentando, ocasionando a junção desses grupos devido à redução no número de participantes - restaram aproximadamente 06 pais.

No primeiro encontro, as estagiárias conversaram com os pais para saber quais eram os temas que eles pretendiam discutir e também lhes mostrar a importância da participação da escola. Em seguida, formaram um círculo e conversaram sobre o tema do dia, em que mães relatavam as próprias experiências cotidianas e as estagiárias intervinham com base nas indicações do supervisor e por meio de pesquisas bibliográficas. Isso resultou na possibilidade de repensar a relação com os filhos em casa. Observa-se no início dos grupos uma relação ainda pautada no estigma social.

Meu filho só pensa em brincar de bolinha de gude, além disso tem ciúmes das irmãs, não posso falar nelas que ele já fica bicudo (relatório final, Elaine e Elizângela, pg. 11). 
Eu primeiro tento conversar com ela, mas quando eu perco a paciência eu bato mesmo (relatório final, Charlene e Rosane, pg. 17).

De acordo com o relato das mães, as estagiárias perceberam que ao longo dos encontros o conhecimento daquelas mães tornou-se mais amplo, pois elas começaram a executar as práticas discutidas no grupo e traziam os resultados que obtiveram.

Eu converso bastante em casa, agora meu filho não está indo brincar só na rua. Valeu ter vindo todos esses dias falar com vocês. Agora ele me abraça e diz para as minhas filhas: minha mãe me ama, né mãe? Eu não vou deixar você 'neivosa". Eu estou me sentindo muito bem (relatório final, Elaine e Elizângela, pg. $11)$ ".

Para encerrar esse grupo foi realizada uma festa de confraternização, que contou também com a participação dos filhos das participantes, que no mesmo horário do grupo de mães estavam no grupo de crianças com a Georgina.

No segundo semestre tentaram montar outro grupo de pais, utilizando o mesmo procedimento do semestre anterior: mandaram bilhetes, torpedos, ligaram e colocaram cartazes na escola, porém não obtiveram sucesso.

Começaram então a trabalhar com as crianças do Pré "A", com o mesmo intuito: discutir temas de acordo com a coleta que realizaram nos primeiros encontros com elas. Primeiramente se apresentaram, estabelecendo vínculo e falaram sobre algumas regras para que os objetivos pudessem ser alcançados. Em seguida, as estagiárias falaram da integração família-escola, conversaram com as crianças sobre as coisas que mais gostavam ou que menos gostavam para poderem discutir nos próximos encontros. Realizada a integração grupal, falaram sobre temas, como ciúmes, disciplina, tolerância e limites, separação ou perdas, diferenças, alimentação e ECA. Esses encontros eram realizados uma vez por semana, tendo um total de dez encontros no primeiro grupo e de oito encontros no segundo grupo. Visto que em cada encontro eram realizadas vivências em grupo, brincadeiras e a 
roda de conversa, onde os participantes falavam sobre seus sentimentos e discutíamos o tema do dia.

As crianças confiavam tanto nas estagiárias que falavam de assuntos familiares como: "Meu pai tá preso" (relatório final, Elaine e Elizângela, 2004, p. 13).

O encontro foi encerrado com uma festa surpresa, com bolos, salgadinhos, refrigerantes, lembrancinhas, músicas e brincadeiras

O grupo da Georgina era formado pelas crianças, cujos pais participavam de encontros com outras estagiárias. No primeiro semestre havia quatro crianças no grupo, foi trabalhada a relação com a família, com a escola, aprendizagem e seu processo, amizade, cooperação, sexualidade, ciúmes e também foi feita uma apresentação de que vem a ser a ECA, APM e Conselho.

Para trabalhar com estes temas, foram desenvolvidas atividades lúdicas com alguns materiais, como: pintura com tintas plásticas, canetas coloridas, jogos, histórias, teatro de fantoches.

No segundo semestre, o grupo tinha doze crianças de cinco anos de idade de uma mesma sala de aula. Georgina trabalhou através do lúdico, os alunos desenvolveram os mesmos temas do primeiro grupo.

Quando começou com estas crianças, elas estavam bem agitadas, agressivas, brigavam muito umas com as outras e também com a estagiária. No decorrer do processo, elas foram percebendo que o tratamento dado pela estagiária era diferente da professora. Era permitida uma maior liberdade, sem perder o respeito e os limites de um convívio tranquiilo. Aos poucos foram entendendo que se exagerassem na liberdade que tinham, acabavam perdendo a mesma e se responsabilizando por isso.

O material utilizado era sempre papel e lápis colorido; brinquedos de montar; giz para desenhar na lousa; fantoches para teatro; grupo de famílias de pano; filmes de vídeo com temas falando de valores, por exemplo, "pinóquio" para falar de mentira, honestidade, confiança e respeito pelo outro.

Charlene e Rosane formaram dois grupos de pais, contando com a participação de aproximadamente nove membros. Já no segundo semestre, desenvolveram o projeto com o terceiro grupo, composto 
em média por sete pais. Neste grupo foi indispensável à elaboração de atividades a serem realizadas com os filhos de alguns dos participantes, pois os mesmos levavam seus filhos aos encontros.

Neste projeto foi desenvolvido também um trabalho com um grupo de crianças matriculadas no primeiro ano do Ensino Fundamental. A formação deste grupo ocorreu por meio da disponibilização da professora que lecionava na classe do primeiro ano vespertino.

Gabriela e Samaia trabalharam juntas de Março a Setembro, a proposta do supervisor era que formassem grupos de pais. Foram realizados 4 encontros semanais com os pais, mas o grupo não permaneceu formado, então deram início ao grupo de crianças.

O grupo consistia em sete crianças no total, com idades diferentes, a cada encontro eram tratados temas diferentes, como: tolerância e limite; ciúmes; sexualidade; integração família-escola; ECA - Estatuto da Criança e do Adolescente; Conselho e APM - Associação de pais e mestres.

As atividades propostas para abordar os temas acima foram: inicialmente utilizaram o Lince $^{1}$ para trabalhar as regras, limites e tolerância. Foi perguntado às crianças o que elas entendiam sobre limite e tolerância: "Quando estou jogando bola na rua tenho hora para entrar em casa, isso é limite".

No segundo encontro foi utilizado o jogo pega vareta como recreação e, depois, foi aberta uma roda de conversa sobre ciúmes. Inicialmente foi pedido que as crianças relatassem o que entendiam sobre ciúmes: "Eu tenho ciúmes da minha avó quando ela abraça meu primo e não me abraça". No quarto encontro foi utilizado o Lince para observar o desenvolvimento operativo das crianças. O quinto encontro foi iniciado com o jogo quebra-cabeça, logo após as estagiárias conversarem com as crianças a respeito do tema integração famíliaescola. No sexto encontro foi discutido o tema da educação sexual através de livros ilustrativos sobre o tema. No sétimo encontro foi abordado o tema Estatuto da criança e do adolescente, o assunto foi ilustrado com um filme e em seguida houve uma discussão. No oitavo encontro foram apresentados e discutidos a APM e o Conselho escolar. No nono encontro foi passado o filme Volta ao mundo com Timão e Pumba, depois do filme foram discutidas questões como amizade, inveja, mentira, roubo e diferentes costumes. 
Em 19/10/2004 a estagiária iniciou atividade individual de acompanhamento às aulas, a atividade se deu no Pré-B com a professora Viviane.

Samaia ficou encarregada de trabalhar com os alunos do Jardim II (alunos de 5 a 6 anos de idade), eram no total 13 alunos. "Fiquei com metade desta sala, pois a estagiária Georgina já estava trabalhando com a outra metade".

Os encontros eram realizados da seguinte forma: primeiro fazia uma roda de conversa com as crianças, perguntando aspectos do cotidiano deles. Depois levava-se jogos, brinquedos, massa de modelar, tinta, caneta hidrocor, lápis e papel, e tentava relacionar o tema às tarefas que eles iriam executar.

Algo que a estagiária observou foi que sempre que a professora deles se aproximava da sala, todos rapidamente sentavam e ficavam estáticos, parecendo que eles tinham medo dela.

\section{CONSIDERAÇÕES FINAIS}

À guisa de conclusão, o que se pretendeu aqui foi retomar alguns aspectos da Integração Família-Escola e fazer um levantamento da importância de um estágio de que trate dessa integração. Conseguimos observar, ao longo da pesquisa feita, que a psicologia, nas suas relações com a educação, parece avançar na busca de maior compreensão do significado do comportamento humano nos contextos de interação, busca-se atender as necessidades educacionais dos indivíduos e grupos, indo além do comportamento manifesto e das contingências imediatas de aprendizagem, preocupando-se com a compreensão dos microsistemas em que a criança está inserida.

A atenção do psicólogo não se centra somente na criança, individualmente considerada como portadora de problemas de aprendizagem, mas se desloca para a escola, para as condições de ensino e para o contexto familiar da criança. Novas formas de atuação estão surgindo, nas quais o psicólogo pode ser um parceiro na orientação escolar e na orientação ao trabalho dos docentes para que estes possam melhor atingir seus objetivos educacionais.

Consideramos a importância de observar os pontos estratégicos 
para a realização do projeto Integração família-escola como, por exemplo: entrevistar e estabelecer vínculos com os pais, professores, funcionários, crianças, para poder ter uma visão ampla do problema e assim organizar estratégias de intervenção. Com base nos questionários destinados aos pais foi possível detectar alguns problemas dentro da instituição e algumas dificuldades familiares existentes, por exemplo, como lidar com o ciúme, com o processo de aprendizagem e a própria importância da família dentro da escola. Por meio desses dados foi possível também notar a impossibilidade de participação dos pais nos instantes em que foram chamados para participarem dos grupos nem todos os pais tinham disponibilidade de tempo para vir à escola. A não participação era justificada pela falta de tempo, sobrecarga de trabalho, jornada dupla de responsabilidade e receio de ser chamado a ir à escola do filho.

Com a realização de grupos de pais foi possível tornar claro para as famílias o quanto essa aproximação ajuda as crianças em seu desenvolvimento escolar e social. Os grupos tiveram o objetivo de desenvolver intervenções visando ações coletivas entre família e escola na busca do equacionamento para problemas educacionais enfrentadas no cotidiano institucional e familiar.

Este trabalho proporcionou às estagiárias envolvidas a possibilidade de adquirir experiência por meio da produção de um espaço de diálogos, de movimentação grupal com pais e crianças, compartilhando com estes anseios as dúvidas e alegrias vivenciadas no cotidiano da comunidade escolar.

\section{Notas}

\footnotetext{
*Doutor em Psicologia Social pela PUC-SP, Docente - Psicologia Social - UNIMEP.

** Psicóloga pelo Centro Universitário Hermínio Ometto - UNIARARAS.

*** Mestre em Educação , Psicóloga Social e Educacional na Associação Metodista de Ação Social - AMAS

${ }^{1}$ Lince é um brinquedo (jogo) para crianças acima de 5 e 6 anos. Constitui-se de um tabuleiro cheio de figuras. Cada jogador recebe 3 figuras e tera que encontrá-las no tabuleiro antes que seus adversários. Para vencer esse jogo a criança terá que ter agilidade e atenção. A criança precisa estar atenta às regras para conseguir um bom desempenho com o brinquedo; assim o mesmo permite observar questões de natureza: regras, limite e tolerância.
} 


\section{Referências}

ARANHA, M.L.A. Filosofia da educação. São Paulo: Ed. moderna, 1998.

ARIÈS, Phlipe. História Social da Criança e da Família. Rio de Janeiro: Livros técnicos e científicos, 1981.

BENCINI, R.. Como atrair os pais para a escola. São Paulo, Abril, 2003.

GUIMARÃES, L.F. Por uma parceria eficiente: família/escola in: Revista Amae Educando, Novembro de 1999- n²88, pág 19-22.

HELlER, A. Sobre os Preconceitos. In O cotidiano e a história. Ed. Paz e Terra, $3^{a}$ edição, Rio de Janeiro, 1989.

MALUF, M.R. Formação e atuação do psicólogo na educação: dinâmica de transformação in: Psicólogo Brasileiro: práticas emergentes e desafios para a formação. Coord. Geral Rosemary Achear, São Paulo, Casa do Psicólogo, 1994.

MOYSÉS, M.A.A. e COLlARES, C.A.L.. Sobre alguns preconceitos no cotidiano escolar. In: Preconceitos no cotidiano escolar: ensino e medicalização. São Paulo/Campinas: Cortez Editora/ Faculdade de Educação, Faculdade de Ciências Médicas, 1996.

PATTO, M.H.S. A criança da Escola Pública: deficiente, diferente ou mal trabalhada? In: SÃO PAULO Secretaria da Educação, Ciclo Básico. São Paulo: SE/CENP, 1990.

REGER, Roger. Psicólogo escolar: educador ou clínico? In: PATTO, M.H.S. Introdução a Psicologia Escolar. São Paulo: T.A. Queiroz, 1981. 
SILVA, Marcos Antônio e VARGAS, Ângelo Luis S. A participação na relação família-escola que viabiliza o processo escolar na educação infantil. In Sprint Magazine, v.20, n.124, p.29-34, jan./fev. 2003.

SIMIONATO-TOZO, Stella Maria Poletti e BISAOLI-ALVES, Zélia Mendes. Alguns Aspectos da escolarização de crianças nas últimas décadas. In Paidéia: Cadernos de Psicologia e Educação, n.10/11, p.29-44, fev./ago. 1996.

SZYMANSKI, H. Práticas educativas familiares: A família como foco de atenção psicoeducacional. In Estudos de Psicologia, v.21, n.2, p.5-16, maio/ago. 2001.

VOLNOVICH, J e HUGUET, C.R. Sociedade, infância e família no final do milênio in Grupos, Infância e Subjetividade. Rio de Janeiro. Relume-Dumará, 1995.

\section{Abstract: \\ SCHOLL-FAMILY INTEGRATION: THE EXPERIENCE OF A PRACTICE ACTIVITY IN EDUCATION AND COMMUNITY}

The school psychologist part is to actuate according to the educator part, helping to improve the quality and efficiency of the educational process through the psychological knowledge application. The purposes of this work, which is related to literature review and documental analysis, are: make investigation of the importance of a project in Family-School integration; to understand how the family can be integrated to school from a probation project; to check if this relationship Family-School to one becomes next from the interventions proposals for the probation reports of the project. The study has scientific and social relevance because it is useful as parameter to other searchers who want to study the Family-School integration, as well the importance of the activities done with the parents searching a better quality in the relationship with their children, as well with the education institution. This survey had as investigation method the bibliographical survey about the problem above mentioned; documental analysis of the diagnosis and 
intervention projects carried out by the probationers who took part of the probation program in 2003 and 2004: in the end the analysis of the final probation reports.

Keywords: Family-School Integration; School and Educational Psychology; Parents and children.

Recebido em 26 de outubro de 2007.

Aceito em 07 de janeiro de 2008. 